\title{
Development and structure of Bacillus subtilis biofilms manipulated by Iron(II) addition during cultivation at different shear stress conditions
}

\author{
Luisa Gierl ${ }^{1}$, Harald Horn ${ }^{2}$, and Michael Wagner ${ }^{3}$ \\ ${ }^{1}$ Karlsruher Institut für Technologie Engler-Bunte-Institut \\ ${ }^{2}$ Karlsruhe Institute of Technology, Germany \\ ${ }^{3}$ Karlsruhe Institute of Technology
}

January 4, 2021

\begin{abstract}
Bivalent ions such as $\mathrm{Ca} 2+$ and $\mathrm{Mg} 2+$ are known to affect the structural and mechanical properties of biofilms. In order to reveal the impact of $\mathrm{Fe} 2+$ ions within the cultivation medium on biofilm development, structure and stability, Bacillus subtilis biofilms were cultivated in mini-fluidic flow cells. Two different Fe2+ inflow concentrations (0.25 and 2.5 mg/L, respectively) and wall shear stress levels (0.05 and $0.27 \mathrm{~Pa}$, respectively) were tested. Biofilm structure was determined daily in situ and noninvasively by means of optical coherence tomography. A set of ten structural parameters was used to quantify biofilm structure, its development and change. Moreover, for each experiment ten replicates were cultivated and analyzed allowing for valid conclusions. Fe2+ addition influenced biofilm development (e.g., biofilm accumulation) and structure markedly. Experiments revealed the accumulation of $\mathrm{FeO}(\mathrm{OH})$ within the biofilm matrix and a positive correlation of $\mathrm{Fe} 2+$ inflow concentration and biofilm accumulation. Even at elevated shear stress levels this correlation was valid. In more detail, independent of the wall shear stress applied during cultivation over ten days biofilms grew approximately four times thicker at 2.5 mg Fe2+/L compared to low $\mathrm{Fe} 2+$ inflow concentrations of $0.25 \mathrm{mg} / \mathrm{L}$. This finding hints on a higher stability of Bacillus subtilis biofilms against detachment when growing at elevated $\mathrm{Fe} 2+$ concentrations.
\end{abstract}

\section{Introduction}

Biofilms are aggregates composed of microorganisms, extracellular polymeric substances (EPS) as well as extracellular DNA. Mainly, they appear at interfaces in watery environments (Flemming, Wingender, \& Szewzyk, 2007). Within the last decade, more attention was paid to biofilms due to their unique properties and potential applications as productive systems (Edel, Horn, \& Gescher, 2019; Rosche, Li, Hauer, Schmid, \& Buehler, 2009). On one hand, these communities have several beneficial features, e.g. (i) in cleaning waste water (Van Loosdrecht \& Heijnen, 1993); (ii) by producing valuable (platform) chemicals (Cuny et al., 2019), (iii) methane (as fuel) (Yeung et al., 2017) or (iv) bioplastics (Hackbarth et al., 2020), too. On the contrary, biofilms can have adverse effects, i.e. on human health by growing on implants or by blocking industrial settings such as water pipes (Azeredo et al., 2016).

In order to optimize biofilm-technological processes it is necessary to understand biofilm proliferation and behavior under certain conditions.

Direct analysis of bioflm behavior or rather structure can be performed using different imaging techniques such as confocal laser scanning microscopy (CLSM), scanning electron microscopy (SEM) or atomic force microscopy (AFM) (Allen, Habimana, \& Casey, 2018; Azeredo et al., 2016; Bridier, Meylheuc, \& Briandet, 2013; Dutta Sinha, Das, Tarafdar, \& Dutta, 2017). While CLSM can be used for investigating the 
biofilm matrix composition (e.g., DNA and EPS) in a range of several micrometers, SEM together with energy-dispersive X-ray spectroscopy (EDX) examines biofilms up to $1 \mathrm{~nm}$ resolution and their elemental composition. AFM determines for instance adhesion forces between biofilm and the substratum as well as cohesive strength (Allen et al., 2018; Azeredo et al., 2016). Optical coherence tomography (OCT) is an application becoming increasingly relevant for the analysis of biofilms' mesoscopic structure as seen from the raising number of publications (Blauert, Horn, \& Wagner, 2015; Dreszer et al., 2015; Haisch \& Niessner, 2007; Wagner \& Horn, 2017; Weiss, Obied, Kalkman, Lammertink, \& van Leeuwen, 2016). Advantages among other imaging techniques are the high optical resolution together with a fast acquisition of 3D datasets of translucent tissues and materials in situ despite large representative volumes. Mesoscopic biofilms are valuable for e.g., modeling of permeate fluxes in membrane systems (Derlon, Peter-Varbanets, Scheidegger, Pronk, \& Morgenroth, 2012) or substrate turnover in biofilm reactors (Li, Wagner, Lackner, \& Horn, 2016; Wagner \& Horn, 2017). Since a statistical survey of biofilm replicates is inevitable for e.g., optimizing parameters in a biofilm production reactor, OCT is the imaging modality of choice for the identification and quantification of structural biofilm parameters.

Nutrients and hydrodynamics are some of the main effectors in biofilm lifecycle. Several studies have been performed which focus on the influence of different ions and flow velocities on biofilm behavior (Guvensen, Demir, \& Ozdemir, 2013; Park, Jeong, Lee, Kim, \& Lee, 2011; Paul, Ochoa, Pechaud, Liu, \& Liné, 2012; Sehar, Naz, Das, \& Ahmed, 2016; Song \& Leff, 2006; P. Stoodley, Dodds, Boyle, \& Lappin-Scott, 1999; P Stoodley, Cargo, Rupp, Wilson, \& Klapper, 2002). Bivalent cations such as $\mathrm{Ca}^{2+}$ and $\mathrm{Mg}^{2+}$ are known to promote growth and stability of biofilms (Guvensen et al., 2013; Sehar et al., 2016; P. Stoodley et al., 1999). Additionally, iron $\left(\mathrm{Fe}^{2+}\right)$ may be of concern regarding biofilm development. Iron is an essential trace element and component of iron-sulfur-complexes in various enzymes. Moreover, a couple of bacteria utilize $\mathrm{Fe}^{3+}$ as an electron acceptor within the respiratory chain (Riemer, Hoepken, Czerwinska, Robinson, \& Dringen, 2004). Furthermore, iron is essential for almost all living organisms and forms a cofactor in many cellular proteins, which are involved in electron transport, detoxification of reactive oxygen species (ROS) or DNA synthesis (Neilands, 1974). For that reason, at least a minimum of iron availability should be necessary for the maturation process of biofilms. The role of iron has been studied by several research institutes, too, mainly applying pathogenic Pseudomonas aeruginosa or static biofilms (e.g., agar plate- and microtiterplate biofilms) with diverging results (Banin, Vasil, \& Greenberg, 2005; Berlutti et al., 2005; Kang \& Kirienko, 2018; Musk, Banko, \& Hergenrother, 2005; Ranmadugala, Ebrahiminezhad, Manley-harris, \& Ghasemi, 2017; L. Yang et al., 2007). Additionally, most studies merely focus on the performance of those biofilms instead of physical structure - although structure and function are closely linked to each other. For instance, Möhle et al. (2007) described a positive effect on the biofilms' stability grown in a rotating disc reactor when higher amounts of iron sulfate $(10 \mathrm{mg} / \mathrm{L})$ were available (Möhle et al., 2007). Further studies showed that a limitation of iron (Singh, Parsek, Greenberg, \& Welsh, 2002; Weinberg, 2004) as well as an excess of iron (Lin, Shu, Huang, \& Cheng, 2012; Musk et al., 2005; L. Yang et al., 2007) in the environment inhibited the formation and development of biofilms in contrast to suspended cells.

In this study, the effect of $\mathrm{Fe}^{2+}$ in the cultivation medium on the development and maturation of Bacillus subtilisflow cell biofilms is investigated in order to evaluate biofilm behavior in terms of structure in 3D and non-invasively. Hence, two different $\mathrm{Fe}^{2+}$ concentrations were used to study the effect on the biofilm's morphology and maturation. This work strengthens the fundamental knowledge about biofilm physical structure and their interaction with interfaces. Furthermore, it highlights iron $\left(\mathrm{Fe}^{2+}\right)$ as an (trace) element, which can be used to control biofilm development and maturation.

\section{Materials and Methods}

\subsection{Biofilm cultivation}

Biofilms were cultivated in custom-made flow cells composed of sticky-Slides (sticky-Slide I 0.4 Luer, ibidi GmbH, Martinsried, Germany) glued to PVC slides (substrata). Sticky-Slides are made from transparent plastic and serve as the cover of the flow cell forming a flow channel with the size of $50 \times 5 \times 0.45 \mathrm{~mm}^{3}$ (length $\times$ width $\times$ height, thickness of the sticky-Slide $=1 \mathrm{~mm}$ ). A number of $N=$ 
10 flow cells were operated for each condition in parallel at volumetric flow rates of $\mathrm{Q}=1 \mathrm{~mL} / \mathrm{min}$ andQ $=$ $5 \mathrm{~mL} / \mathrm{min}$, respectively (equals mean flow velocities of $\mathrm{u}=0.75 \mathrm{~cm} / \mathrm{s}$ and $u=3.75 \mathrm{~cm} / \mathrm{s}$, respectively).

Flow cells were inoculated with Bacillus subtilis pre-cultures grown at $37^{\circ} \mathrm{C}$ overnight in Luria Broth (LB) medium. Cells were grown to exponential phase; $10 \mathrm{~mL}$ of this pre-culture together with a minimal salts glycerol medium in a mixing ratio of 1:500 were used as inoculation solution. The cultivation medium was adapted from (Wang, Wang, \& Hao, 2015) and contained (concentration in $\mathrm{mg} / \mathrm{L}$ ): $\mathrm{MnCl}_{2} * 4 \mathrm{H}_{2} \mathrm{O}$ (10), L-phenylalanine (5), glycerol (5), $\mathrm{MgCl}_{2} * 6 \mathrm{H}_{2} \mathrm{O}$ (4), L-tryptophane (3.5) with diverging concentrations of $\mathrm{FeCl}_{2} * 4 \mathrm{H}_{2} \mathrm{O}$ ([?] 0.25 and $2.5 \mathrm{mg} / \mathrm{L} \mathrm{Fe}^{2+}$ ) in tap water. Salt concentrations of the tap water of Karlsruhe are accessible from the homepage of the Stadtwerke Karlsruhe (https://www.stadtwerke-karlsruhe.de) and contained (mg/L): Ca (112), Na (11), Mg (9.7), Si (5.4), K (1.7), P $(<0.01)$, Fe $(<0.01)$ and $\mathrm{Mn}(<0.005)$.

Flow cells were flushed with the inoculum for $15 \mathrm{~min}$. Afterwards flow was stopped for $1 \mathrm{~h}$ giving bacteria the possibility to settle. Then biofilm cultivation started in flow-through mode. Biofilm development $25 \mathrm{~mm}$ downstream the inlet was monitored daily for ten consecutive days by means of OCT using the EvoBot platform (Faina et al., 2016; Gierl, Stoy, Faina, Horn, \& Wagner, 2020). An overview of the conducted experiments is provided in Table 1.

\subsection{Optical coherence tomography and image processing}

Optical Coherence Tomography (OCT) is a 3D imaging technique that allows for the non-invasive, realtime imaging of the mesoscopic biofilm structure (Martin, Bolster, Derlon, Morgenroth, \& Nerenberg, 2014; Wagner \& Horn, 2017). A brief summary regarding the working principle of OCT has already been provided in (Blauert et al., 2015; Gierl et al., 2020).

A spectral domain tomograph (GANYMEDE I, Thorlabs GmbH, Dachau, Germany) with an optical resolution of $8 \times 8 \times 2.1 \mathrm{~m}^{3}(\mathrm{x} \times \mathrm{y} \times \mathrm{z}$, LSM03 objective lens $)$ in water $(n=1.33)$ was used to monitor biofilm development. OCT images (A-scan averaging $=3$ ) with a size of $7 \times 6 \times 0.5 \mathrm{~mm}^{3}$ were acquired on a daily basis. Image post-processing included the calculation of structural biofilm parameters. OCT datasets were cropped to a volume of $7 \times 5 \times 0.25 \mathrm{~mm}^{3}$ (due to autocorrelation artifacts). A mean filter with a radius of 2 px was applied and binary datasets were generated using Fiji (Schindelin et al., 2012). Substratum coverage (SC), mean biofilm thickness $\left(L_{F}\right)$, textural entropy (TE), kurtosis $\left(R_{\mathrm{KU}}\right)$, skewness $\left(R_{\mathrm{SK}}\right)$, fractal dimension (FD), angular second moment $(A S M)$, inverse difference moment $(I D M)$ as well as average horizontal $(A H R L)$ and average vertical run lengths $(A V R L)$ were calculated from binary datasets according to (Wagner \& Horn, 2017), (Blauert et al., 2015) and by use of the MiToBo plugin (Fiji) for biofilms (Möller, Glaß, Misiak, \& Posch, 2016). In-house macros were used to render topographic representations of OCT C-scans (e.g., height maps representing the bulk-biofilm interface) (Wagner \& Horn, 2017).

An overview of all structural parameters and their calculation is given in (Beyenal, Donovan, Lewandowski, \& Harkin, 2004; Wagner \& Horn, 2017; X. Yang, Beyenal, Harkin, \& Lewandowski, 2000). ParametersSC, $R_{\mathrm{KU}}$ and $R_{\mathrm{SK}}$ were analyzed using Fiji's plugin function "analyze". An overview regarding the interpretation of the structural biofilm parameters is presented below (see Table 2).

\subsection{Analysis of variance (ANOVA) and Scheirer-Ray-Hare}

Grubb's tests and normality tests (Shapiro-Wilk) were performed in Origin to identify and discard outliers (OriginPro, Version 2018G, OriginLab 275 Corporation, Northhampton, MA, USA). Two factorial variance analyses with measuring repetitions were performed to evaluate the influence of $\mathrm{Fe}^{2+}$ and flow velocity on biofilm development and structure. In case of non-normality, a Scheirer-Ray-Hare test was applied. Three hypotheses were picked with the following predications:

$\mathrm{H}_{1}$ : No differences in structure due to usage of different flow velocities $u$

$\mathrm{H}_{2}$ : No differences in structure due to usage of different iron concentrations $c$

$\mathrm{H}_{3}$ : No correlation between both parameters $u$ and $c$ 
To determine the approval or rejection of the hypotheses, calculated $p$-values were compared to a significance level of $\alpha<0.01$, whereby values $\mathrm{p}<\alpha$ describe the rejection of the individual hypothesis. Variance analyses were performed in Excel (Excel version 15.11, Microsoft Corporation, Washington, USA).

\section{Results and Discussion}

\subsection{Structural differences in OCT-imaged biofilms}

Four growth conditions were applied to biofilms that differed in volumetric flow rate $Q$ and the $\mathrm{Fe}^{2+}$ concentrationc (see Table 1). The aim of the study was the identification of a dependency of biofilm development and structure in terms of inflowing $\mathrm{Fe}^{2+}$ as well as of different flow regimes. Figure 1 illustrates height maps showing the topography of the developed biofilms at day 10 for each flow cell under each applied condition. Images of all flow cells on each day are given in Supplementary Information Figure 1.

Figure 1 reveals biofilm growth in all flow cells. To be noticed, FC 9 of E4 had a different appearance among the other flow cells for these experimental conditions. The same is visible from E3 in FC 5 among FCs 8 and 10. Experiment E1 $\left(c=2.5 \mathrm{mg} / \mathrm{L} \mathrm{Fe}^{2+}, u=0.75 \mathrm{~cm} / \mathrm{s}\right)$ depicts biofilms with a mean biofilm thickness $L_{F}=$ $75 \mu \mathrm{m}$ in all replicates. Additionally, under condition E1, biofilm aggregates of $L_{F}$ up to $200 \mu \mathrm{m}$ established and the substratum was covered with heterogeneous aggregates, ranging from smaller and spherical colonies to longer $(>2 \mathrm{~mm})$ and elliptic colonies. In experiment E2 $\left(c=0.25 \mathrm{mg} / \mathrm{L} \mathrm{Fe}^{2+}, u=0.75 \mathrm{~cm} / \mathrm{s}\right)$ less biofilm developed and merely FC 1, FC 2 and FC 5 to 7 are covered with biofilm $\left(L_{F}=50 \mu \mathrm{m}\right)$. In comparison to E1, biofilm growth within E2 started delayed and only small colonies of minor widths and lengths, as well as of minor heights accumulated. In E3 $\left(c=2.5 \mathrm{mg} / \mathrm{L} \mathrm{Fe}^{2+}, u=3.75 \mathrm{~cm} / \mathrm{s}\right)$ in turn, biofilm growth seemed to be more dense at day 10 of the growth course. Likewise E2, bacterial colonization was first visible around days 3 and 4 . Here, accretion of the flow chamber took place from the walls to the center of the FC, probably due to the higher flow velocity. In $\mathrm{E} 4\left(c=0.25 \mathrm{mg} / \mathrm{L} \mathrm{Fe}^{2+}, u=3.75 \mathrm{~cm} / \mathrm{s}\right)$, coverage of the substratum was again low as in E2 and only a few colonies randomly developed with high biofilm thicknesses of $L_{F}=200$ $\mu \mathrm{m}$.

Figure 1 already provides visible differences in growth patterns for different experimental conditions. However, for quantification of the influence of flow velocity (shear stress) and iron $\left(\mathrm{Fe}^{2+}\right)$ dosage on biofilm structure and development several structural parameters have been calculated (confer Materials \& Methods). Those are presented in Figure 2 and discussed in the following.

In Figure 2, the development of 10 different structural biofilm parameters for all conditions E1-E4 are illustrated. As already visible in Figure 1, the effect of the high $\left(\mathrm{E} 1+\mathrm{E} 3, c=2.5 \mathrm{mg} / \mathrm{L} \mathrm{Fe}^{2+}\right)$ and the low iron(II) concentration $\left(\mathrm{E} 2+\mathrm{E} 4, c=2.5 \mathrm{mg} / \mathrm{L} \mathrm{Fe}^{2+}\right)$ is visible. While mean biofilm thickness $L_{F}$ and substratum coverageSC of $\mathrm{E} 1$ and $\mathrm{E} 3$ show a steady increase until the end of the experiment, those parameters stay at a minimum level in E2 and E4. A similar trend is distinct for the parameters textural entropyTE, average horizontal AHRL and average vertical run length AVRL. Additionally, stated parameters of E3 ( $c=$ $\left.2.5 \mathrm{mg} / \mathrm{L} \mathrm{Fe}^{2+}, u=3.75 \mathrm{~cm} / \mathrm{s}\right)$ exceed those of E1 $\left(c=2.5 \mathrm{mg} / \mathrm{L} \mathrm{Fe}^{2+}, u=0.75 \mathrm{~cm} / \mathrm{s}\right)$ at the end of the experiment (from day 8 to day 10). The same trend is shown for biofilms grown with $c=0.25 \mathrm{mg} / \mathrm{L}$ $\mathrm{Fe}^{2+}$, whereas mentioned structural parameters in E4 $(u=3.75 \mathrm{~cm} / \mathrm{s})$ exceed those of E2 $(u=0.75 \mathrm{~cm} / \mathrm{s})$.

While mean biofilm thickness $L_{F}$ and substratum coverageSC indicate an early accumulation of biofilms with high biofilm volume in $\mathrm{E} 1$ and $\mathrm{E} 3\left(c=2.5 \mathrm{mg} / \mathrm{L} \mathrm{Fe}^{2+}\right)$, higher values of textural entropy TE exhibit more heterogeneous biofilms. Thus, biofilms grown with $2.5 \mathrm{mg} / \mathrm{L} \mathrm{Fe}^{2+}$ show more differentiated and partially distributed structures. Furthermore, average run lengths AHRLand AVRL of biofilms in E1 and E3 display longer and wider biofilm aggregates resulting in the largest aggregates regarding biofilm volume in E3 $(c=$ $2.5 \mathrm{mg} / \mathrm{L} \mathrm{Fe}^{2+}, u=3.75 \mathrm{~cm} / \mathrm{s}$ ) (compare Figure 1).

As seen from the structural parameters skewness $R_{\mathrm{SK}}$ and kurtosis $R_{\mathrm{KU}}$, biofilms in E4 $(c=0.25 \mathrm{mg} / \mathrm{L}$ $\mathrm{Fe}^{2+}, u=3.75 \mathrm{~cm} / \mathrm{s}$ ) displayed random distributed and high biofilm hills with a low substratum coverage $\mathrm{SC}$ at the beginning of the experiment. From day 5 to the end of the experiment (day 10), values of $R_{\mathrm{SK}}$ and $R_{\mathrm{KU}}$ under all conditions approximate and stay near zero. Thereby, a homogeneous distribution of biofilm 
as well as an equalized ratio of colonies with either low or high biofilm thickness $L_{F}$, except for E2 $(c=0.25$ $\mathrm{mg} / \mathrm{L} \mathrm{Fe}^{2+}, u=0.75 \mathrm{~cm} / \mathrm{s}$ ) where only several high and small biofilm aggregates occurred, is confirmed (compare Figure 1). Again, structural biofilm parameters fractal dimension FD, angular second moment ASMand inverse difference moment IDM prove a lucid differentiation between biofilms grown with $c=0.25$ $\mathrm{mg} / \mathrm{L} \mathrm{Fe}^{2+}$ and $c=2.5 \mathrm{mg} / \mathrm{L} \mathrm{Fe}^{2+}$. Higher values of FD up to 1.8 in $\mathrm{E} 1$ and $\mathrm{E} 3\left(c=2.5 \mathrm{mg} / \mathrm{L} \mathrm{Fe}^{2+}\right)$ explain more irregular surfaces of the aggregates (compare Table 2). Here, the parameter ASMdescribes a change in growth direction (additional growth in y-direction (width)) and IDM proves additional growth in width, since distances between cell clusters are minimizing to the end of the experiment, compared to E2 and $\mathrm{E} 4\left(c=0.25 \mathrm{mg} / \mathrm{L} \mathrm{Fe}^{2+}\right)$.

As can be seen, biofilm thickness $L_{F}$ and/or surface coverage SC, which are typically used for characterization of biofilm structure, do not provide the complete information on biofilm development. Therefore, only the joint consideration of all evaluated structural parameters leads to a complete overview of biofilm development over the cultivation period of 10 days. Figure 2 shows, that at the beginning, biofilms cultivated at $u=$ $3.75 \mathrm{~cm} / \mathrm{s}$ (E3, E4) developed more slowly due to the higher shear stress. However, towards the end of the experiment (days 8 to 9 ) those biofilms became more stable in terms of $L_{F}$, SC, ASM and IDM in relation to biofilms in E1 and E2 $(u=0.75 \mathrm{~cm} / \mathrm{s})$. With regard to the different iron(II) concentrations, more unambiguous differences in mostly all structural parameters could be identified (correlation of E1 + E3 and $\mathrm{E} 2+\mathrm{E} 4)$. The results confirm the positive influence of $\mathrm{Fe}^{2+}$ on biofilm accumulation and differentiation. Likewise (Körstgens, Flemming, Wingender, \& Borchard, 2001) showed, that bivalent cations (e.g., $\mathrm{Ca}^{2+}$ ) enhance the stability of the biofilm matrix in Pseudomonas aeruginosabiofilms which could explain the increased adhesion and biofilm accumulation in E1 and E3 $\left(c=2.5 \mathrm{mg} / \mathrm{L} \mathrm{Fe}^{2+}\right)$ of the presented study. Additionally, in the study by (Möhle et al., 2007), increased concentrations of iron sulfate in the nutrient medium ( $c=10 \mathrm{mg} / \mathrm{L}$ ) prevented sloughing of microbial biofilms (activated sludge) in a rotating disk reactor. Furthermore, the authors documented the dependence of the biofilm thickness from the substrate concentrationc as well as from the shear stress on the biofilm surface. Beyond, in studies with iron complexing agents it was found that a minimal concentration of soluble iron is necessary for the formation of $P$. aeruginosa biofilms in flow cells (Renslow, Lewandowski, \& Beyenal, 2011; Singh et al., 2002; L. Yang et al., 2007). Thereby, one theory is, that iron regulates the surface motility of the bacteria and again promotes the biofilm formation by stabilizing the EPS matrix, which mainly consists of negatively charged polymers (Berlutti et al., 2005; Lin et al., 2012; Singh, 2004; Weinberg, 2004).

These studies further show, that an excess of iron concentrations inhibits biofilm formation, too, since the release of DNA from dead $P$. aeruginosa cells is suppressed. This release is an important structural component of biofilms (Lin et al., 2012; L. Yang et al., 2007). However, an ideal iron concentration in culture medium cannot easily be determined. While (Berlutti et al., 2005) define "high" iron concentrations in a range of $0.55-5.5 \mathrm{mg} / \mathrm{L}$ as positive in terms of aggregation and manipulation of biofilm development and structure in different reactor systems and tests, (L. Yang et al., 2007) reported an inhibition of biofilm growth in microtiter plates and flow cells in this concentration range. In the present study, this inhibition by high iron concentrations cannot be proven. Presumably, an addition of iron $\left(\mathrm{Fe}^{2+}\right)$ does not stimulate every bacterial biofilm system or possibly optimum iron amounts can vary among different biofilm species. Nevertheless, (Weinberg, 2004) confirmed that zinc, manganese and iron have key functions in biochemical as well as in morphological conversion of pro- and eucaryotes, respectively. Since soil carries high amounts of iron, a positive influence on growth of the used soil bacterium Bacillus subtilis could be demonstrated in the present study (Kolodkin-Gal et al., 2013; Pelchovich, Omer-Bendori, \& Gophna, 2013; Rizzi, Roy, Bellenger, \& Beauregard, 2019).

Likewise, the influence of hydrodynamics on biofilms is well-known and documented in several studies (Manz, Volke, Goll, \& Horn, 2003; Park et al., 2011; Paul et al., 2012; Purevdorj, Costerton, \& Stoodley, 2002; P. Stoodley et al., 1999; P Stoodley et al., 2002; Teodósio, Simões, Melo, \& Mergulhão, 2011; Weiss et al., 2016). These studies verify the formation of streamers at higher flow velocities meaning increased growth in length, which is best visible in E3 for FC 8 and E4 for FC $9(u=3.75 \mathrm{~cm} / \mathrm{s}$, see Figure 1 and Figure 
2 AHRL). Statements about the viscoelastic properties and strength of the cell clusters characterize the positive influence of the hydrodynamics furthermore (Allen et al., 2018; Peterson et al., 2015; Rupp, Fux, \& Stoodley, 2005; Safari, Tukovic, Walter, Casey, \& Ivankovic, 2015; P Stoodley et al., 2002; Paul Stoodley, Lewandowski, Boyle, \& Lappin-scott, 1999; Towler, Rupp, Cunningham, \& Stoodley, 2003).

\subsection{ANOVA-confirmed effects of iron(II) on biofilm structure}

Two factor-based variance analyses were performed to verify the results of the structural biofilm parameters given in Figure 2. These evaluations determine to which extent a correlation of the conditions $(c, u)$ took place. Furthermore, they provide insight on the differentiation of structural biofilm parameters between conditions with statistical certainty.

A $p$-value above the significance level $\alpha_{0.01}$ proves that the hypothesis is accepted and that no differences in structural biofilm parameters can be estimated by the chosen condition. This was shown by both the ANOVA and the Scheirer-Ray-Hare test for all structural parameters in hypothesis $\mathrm{H}_{1}$ (Table 3 ).

With a minimum value of the skewness parameter with $R_{\mathrm{SK}}(p=0.07>\alpha)$ up to a maximum value of the substratum coverage SC $(p=0.84>\alpha)$, there were no statistically significant differences between the low $(u=0.75 \mathrm{~cm} / \mathrm{s})$ and high flow velocity $(u=3.75 \mathrm{~cm} / \mathrm{s})$. On closer consideration of $R_{\mathrm{SK}}$ in Figure 2 , it gets visible that this parameter showed the lowest $p$-value in $\mathrm{H}_{1}$ because there was no overlapping of the standard deviations of E1 + E3 as well as of E2 + E4 at the end of the experiment. This documents that the volumetric flow rate and resulting shear stress $\tau_{w}$ have a slight influence on the biofilms regarding skewness $R_{\mathrm{SK}}$ and the fractal dimensionFD. Nevertheless, this could not be confirmed with statistical significance compared to the influence of $\mathrm{Fe}^{2+}$ on the biofilm aggregates (see Table $3, \mathrm{H}_{2}$ ). In comparison to Figure $2, \mathrm{Fe}^{2+}$ has a positive effect on the mean biofilm thickness $L_{F}$ and substratum coverageSC, which basically means on biofilm accumulation.

In contrast, diagrams of skewness $R_{\mathrm{SK}}$ and kurtosis $R_{\mathrm{KU}}$ revealed the smallest differences between conditions E1-E4 at the end of the experiments. This is confirmed by the ANOVA for $R_{\mathrm{SK}}$ with the closest value to $\alpha(p$ $\left.=0.18 \cdot 10^{-2}<\alpha\right)$ in $\mathrm{H}_{2}$. The value of $R_{\mathrm{KU}}$, on the other hand, is far from the significance level $\left(p=0.56 \cdot 10^{-5}<\right.$ $\alpha$ ), although the experimental course of $R_{\mathrm{KU}}$ resembled the development of $R_{\mathrm{SK}}$ in Figure 2. One reason might be the use of the Scheirer-Ray-Hare test, which is generally considered to be less accurate than the ANOVA (Dytham, 2011). The results of $\mathrm{H}_{3}$ again show, as is evident from $\mathrm{H}_{1}, p$-values above the significance level $\alpha$. This verifies the assumption that the influence of the volume flow and the addition of $\mathrm{Fe}^{2+}$ do not correlate with one another. Solely, the value of the average horizontal run lengthAHRL is relatively approximate to the level of significance $(p=0.04<\alpha)$. An explanation is given by the non-changing direction of water flow in the channel: preferably, the aggregates are growing in $x$-direction if sufficient addition of $\mathrm{Fe}^{2+}$ is present, as the flow is unidirectional.

The investigation of the fluid-structure interaction demonstrates the need to analyze a large number of biofilm structural parameters since the evaluation of one parameter may (possibly) not be sufficient to determine differences or rather dependencies and correlations (e.g., $R_{\mathrm{SK}}, R_{\mathrm{KU}}$ ). Additionally, the choice of a statistical test like an ANOVA will prove the occurrence of underlying relations.

\subsection{Influence of Fe amounts and compounds on biofilm development}

Further gravimetrical determinations as well as ion chromatography (ICP-OES) verified that $\mathrm{Fe}^{2+}$ is somehow stored into the biofilm matrix and not rinsed out with the nutrient medium flowing through (data not shown). Here, most of the iron was incorporated in biofilms of experiments E1 and E3 $\left(c=2.5 \mathrm{mg} / \mathrm{L} \mathrm{Fe}^{2+}\right)$. Several hypotheses were postulated that describe the uptake and influence of iron into the biofilm. For instance, (Kang \& Kirienko, 2018) confirm an uptake of iron via siderophores (iron carriers) as well as the storage of iron inPseudomonas aeruginosa biofilms. (Rizzi et al., 2019) report thatBacillus subtilis utilizes the formation of biofilms and the production of siderophores to take up iron (Fe) from the medium, likewise to ensure normal growth. Thereby the authors define iron (Fe) as the most important metal in biology (Rizzi et al., 2019). Additionally, (Oh, Andrews, \& Jeon, 2018) found out that iron promotes biofilm formation through oxidative 
stress and that it stimulates EPS production in Campylobacter jejuni . Hence, in their study an addition of iron significantly supported the formation of microcolonies in the early stage as well as the differentiation into mature biofilm structures, which is reflected here both by the OCT as well as the analysis of the structural biofilm parameters.

Additionally, measurements of the individual biofilms via attenuated total reflectance infrared spectroscopy (ATR-IR) were performed (data presented in SI Figure 2). It was verified that experiments E1 and E3 ( $c=2.5$ $\left.\mathrm{mg} / \mathrm{L} \mathrm{Fe}^{2+}\right)$ as well as E2 and E4 $\left(c=0.25 \mathrm{mg} / \mathrm{L} \mathrm{Fe}^{2+}\right)$ are correlating, respectively, which coincidences with the results of the growth experiment (Figure 2). According to literature, Fe is mainly incorporated into the biofilms via polymorphs of iron oxide-hydroxides (x-FeOOH) (Chan, Stasio, Welch, Fakra, \& Banfield, 2004; Florea et al., 2011; Neu et al., 2010; Omoike, Chorover, Kwon, \& Kubicki, 2004). Thereby, in experiments $\mathrm{E} 1$ and $\mathrm{E} 3$ an incorporation of $\alpha-\mathrm{FeOOH}$ took place, whereas in $\mathrm{E} 2$ and $\mathrm{E} 4 \beta$ - $\mathrm{FeOOH}$ was stored into the biofilms. This was found in (Wagner, 2011) and (Ivleva, Wagner, Horn, Niessner, \& Haisch, 2010), too, whereby the authors documented an incorporation of $\gamma$-FeOOH into waste water biofilms. As maintained by (Wagner, 2011) and (Mohle et al., 2007), cross-linking of iron with the biofilm matrix ensured an increased stability of the biofilms. $\alpha$-FeOOH is a highly reactive compound and (Omoike et al., 2004) proved that an interaction of Bacillus subtilisbiofilms with $\alpha$-FeOOH ensures an energetically stable connection for further EPS- and cell adhesion. This made it possible for the biofilms in E1 and E3 $\left(c=2.5 \mathrm{mg} / \mathrm{L} \mathrm{Fe}^{2+}\right)$ to grow increasingly and to remain stable even at a high flow velocity $(u=3.75 \mathrm{~cm} / \mathrm{s})$ without sloughing events of microcolonies. With its loose structure, $\beta$-FeOOH exhibited the ability to store high amounts of water (Mei, Liao, Wang, \& Xu, 2015). Thus, the low addition of iron(II) in E2 and $\mathrm{E} 4\left(c=0.25 \mathrm{mg} / \mathrm{L} \mathrm{Fe}^{2+}\right)$ as well as the storage of $\beta$-FeOOH into the matrix could be reasons for the reduced accumulation of biofilm mass. Potentially, the type of $\mathrm{x}-\mathrm{FeOOH}$ incorporation is concentration-dependent and dependent of the bacterial organism or its (cell) surface because absorptions were clearly distant from each other, as pointed in (Mei u. a., 2015), too.

\section{Conclusion}

Bacillus subtilis biofilms were cultivated at $\mathrm{Fe}^{2+}$ inflow concentrations of 0.25 and $2.5 \mathrm{mg} / \mathrm{L}$, respectively, as well as at wall shear stress levels of 0.05 and $0.27 \mathrm{~Pa}$, respectively. Structure development was successfully monitored by means of optical coherence tomography and quantified by a large set of ten structural parameters. Through analysis of ten replicates the following conclusions are drawn:

1. Iron is - independently of its concentration - incorporated and accumulated within the biofilm matrix as modifications of $\mathrm{FeO}(\mathrm{OH})$. Bacillus subtilis biofilms cultivated in this study showed the accumulation of $\alpha-$ and $\beta-\mathrm{FeO}(\mathrm{OH})$.

2. $\mathrm{FeO}(\mathrm{OH})$ seems to provide cross-linking abilities and may thrive EPS production enhancing the adhesive as well as cohesive strength of investigated biofilms.

3. A positive correlation between the $\mathrm{Fe}^{2+}$ inflow concentration and biofilm development/accumulation partially compensates increased detachment of biofilm at elevated wall shear stress levels.

\section{Acknowledgements}

This work was funded by the German Research Foundation (DFG), grant no. HO 1910/16-1. Special thanks go to Dr. Markus Glaß from the institute of Molecular Cell Biology in Halle (Saale) supporting the generation of Fiji plugins for the analysis of the structural biofilm parameters.

There is no conflict of interest to disclose.

\section{Nomenclature}

$\alpha$ significance level

AFM Atomic Force Microscopy

ANOVA ANalysis Of VAriance 
ATR-IR Attenuated Total Reflectance Infrared Spectroscopy

$c$ concentration $(\mathrm{mg} / \mathrm{L})$

CLSM Confocal Laser Scanning Microscopy

E1-E4 Experiments E1 to E4

EDX Energy-Dispersive X-ray microanalysis

EPS Extracellular Polymeric Substances

FC Flow Cell

$\mathrm{Fe}^{2+} \operatorname{Iron}(\mathrm{II})$

$\mathrm{H}_{1}-\mathrm{H}_{3}$ Hypotheses 1 to 3 for the ANOVA

ICP-OES Inductively Coupled Plasma Optical Emission Spectroscopy

LB Luria Broth

MIP Maximum Intensity Projection (height map)

OCT Optical Coherence Tomography

$p$ exceedance probability (significance value)

PVC Poly-Vinyl-Chloride

ROS Reactive Oxygen Species

$Q$ volumetric flow rate $(\mathrm{mL} / \mathrm{min})$

SEM Scanning Electron Microscopy

$\tau_{w}$ wall shear stress in flow cells $(\mathrm{Pa})$

$u$ flow velocity $(\mathrm{cm} / \mathrm{s})$

$\mathrm{x}$-FeOOH iron oxide-hydroxide polymorph

\section{References}

Allen, A., Habimana, O., \& Casey, E. (2018). The effects of extrinsic factors on the structural and mechanical properties of Pseudomonas fluorescens biofilms: A combined study of nutrient concentrations and shear conditions. Colloids and Surfaces B: Biointerfaces ,165 , 127-134. https://doi.org/10.1016/j.colsurfb.2018.02.035

Azeredo, J., Azevedo, N. F., Briandet, R., Cerca, N., Coenye, T., Costa, A. R., .. Sternberg, C. (2016). Critical review on biofilm methods. Critical Reviews in Microbiology , 0 (0), 1-39. https://doi.org/10.1080/1040841X.2016.1208146

Banin, E., Vasil, M. L., \& Greenberg, E. P. (2005). From The Cover: Iron and Pseudomonas aeruginosa biofilm formation. Proceedings of the National Academy of Sciences , 102 (31), 11076-11081. https://doi.org/10.1073/pnas.0504266102

Berlutti, F., Morea, C., Battistonp, A., Sarli, S., Cipriani, P., Supertp, F., \& Valentp, P. (2005). IRON AVAILABILITY INFLUENCES AGGREGATION, BIOFILM, ADHESION AND INVASION OF PSEUDOMONAS AERUGINOSA AND BURKHOLDERIA CENOCEPACIA. International Journal of Immunopathology and Pharmacology , 18 (4), 661-670.

Beyenal, H., Donovan, C., Lewandowski, Z., \& Harkin, G. (2004). Three-dimensional biofilm structure quantification. Journal of Microbiological Methods , 59 , 395-413. https://doi.org/10.1016/j.mimet.2004.08.003 
Blauert, F., Horn, H., \& Wagner, M. (2015). Time-resolved biofilm deformation measurements using optical coherence tomography.Biotechnology and Bioengineering , 112 (9), 1893-1905. https://doi.org/10.1002/bit.25590

Bridier, A., Meylheuc, T., \& Briandet, R. (2013). Realistic representation of Bacillus subtilis biofilms architecture using combined microscopy (CLSM, ESEM and FESEM). Micron , 48 , 65-69. https://doi.org/10.1016/j.micron.2013.02.013

Chan, C. S., Stasio, G. De, Welch, S. a, Fakra, S., \& Banfield, J. F. (2004). Microbial Polysaccharides Template Assembly of Nanocrystal Fibers. Science , 303 , 1656-1658. https://doi.org/10.1126/science.1092098

Cuny, L., Pfaff, D., Luther, J., Ranzinger, F., Ödman, P., Gescher, J., .. Hille-Reichel, A. (2019). Evaluation of productive biofilms for continuous lactic acid production. Biotechnology and Bioengineering , 116 (10), 2687-2697. https://doi.org/10.1002/bit.27080

Derlon, N., Peter-Varbanets, M., Scheidegger, A., Pronk, W., \& Morgenroth, E. (2012). Predation influences the structure of biofilm developed on ultrafiltration membranes. Water Research ,46 , 3323-3333. https://doi.org/10.1016/j.watres.2012.03.031

Dreszer, C., Wexler, A. D., Drusová, S., Overdijk, T., Zwijnenburg, A., Flemming, H.-C., ... Vrouwenvelder, J. S. (2015). In-situ biofilm characterization in membrane systems using Optical Coherence Tomography: Formation, structure, detachment and impact of flux change. Water Research , 67, 243-254. https://doi.org/10.1016/j.watres.2014.09.006

Dutta Sinha, S., Das, S., Tarafdar, S., \& Dutta, T. (2017). Monitoring of Wild Pseudomonas Biofilm Strain Conditions Using Statistical Characterization of Scanning Electron Microscopy Images.Industrial and Engineering Chemistry Research , 56 (34), 9496-9512. https://doi.org/10.1021/acs.iecr.7b01106

Dytham, C. (2011). Choosing and Using Statistics A Biologist's Guide (3rd ed.). Wiley-Blackwell.

Edel, M., Horn, H., \& Gescher, J. (2019). Biofilm systems as tools in biotechnological production. Applied Microbiology and Biotechnology , 103 (13), 5095-5103. https://doi.org/10.1007/s00253-019-09869-x

Faina, A., Nejatimoharrami, F., Stoy, K., Theodosiou, P., Taylor, B., \& Ieropoulos, I. (2016). EvoBot: An Open-Source, Modular Liquid Handling Robot for Nurturing Microbial Fuel Cells, (July), 626-633. https://doi.org/10.7551/978-0-262-33936-0-ch099

Flemming, H. C., Wingender, J., \& Szewzyk, U. (2007). Biofilm Highlights - Springer Series on Biofilms Series . 5 . https://doi.org/10.1007/b136878

Florea, L. J., Noe-Stinson, C. L., Brewer, J., Fowler, R., Kearns, J. B., \& Greco, A. M. (2011). Iron oxide and calcite associated with Leptothrix sp. biofilms within an estavelle in the upper Floridan aquifer. International Journal of Speleology , 40 (2), 205-219. https://doi.org/10.5038/1827-806X.40.2.12

Gierl, L., Stoy, K., Faína, A., Horn, H., \& Wagner, M. (2020). An open-source robotic platform that enables automated monitoring of replicate biofilm cultivations using optical coherence tomography. Npj Biofilms and Microbiomes , 18 , 1-9. https://doi.org/10.1038/s41522-020-0129-y

Guvensen, N. C., Demir, S., \& Ozdemir, G. (2013). Effects of Magnesium and Calcium Cations on Biofilm Formation by Sphingomonas paucimobilis from an Industrial Environment. Fresenius Environmental Bulletin ,21 (12), 3685-3692.

Hackbarth, M., Jung, T., Reiner, J. E., Gescher, J., Horn, H., Hille-Reichel, A., \& Wagner, M. (2020). Monitoring and quantification of bioelectrochemical Kyrpidia spormannii biofilm development in a novel flow cell setup. Chemical Engineering Journal ,390 (124604), 1-7. https://doi.org/10.1016/j.cej.2020.124604

Haisch, C., \& Niessner, R. (2007). Visualisation of transient processes in biofilms by optical coherence tomography. Water Research ,41 , 2467-2472. https://doi.org/10.1016/j.watres.2007.03.017 
Ivleva, N. P., Wagner, M., Horn, H., Niessner, R., \& Haisch, C. (2010). Raman microscopy and surfaceenhanced Raman scattering (SERS) for in situ analysis of biofilms. Journal of Biophotonics ,3 (8-9), 548556. https://doi.org/10.1002/jbio.201000025

Kang, D., \& Kirienko, N. V. (2018). Interdependence between iron acquisition and biofilm formation in Pseudomonas aeruginosa. Journal of Microbiology , 56 (7), 449-457. https://doi.org/10.1016/j.physbeh.2017.03.040

Kolodkin-Gal, I., Elsholz, A. K. W., Muth, C., Girguis, P. R., Kolter, R., \& Losick, R. (2013). Respiration control of multicellularity in Bacillus subtilis by a complex of the cytochrome chain with a membraneembedded histidine kinase. Genes and Development ,27 , 887-899. https://doi.org/10.1101/gad.215244.113

Körstgens, V., Flemming, H.-C., Wingender, J., \& Borchard, W. (2001). Influence of calcium ions on the mechanical properties of a model biofilm of mucoid Pseudomonas aeruginosa. Water Science and Technology , 43 (6), 49-57. https://doi.org/10.2166/wst.2001.0338

Li, C., Wagner, M., Lackner, S., \& Horn, H. (2016). Assessing the Influence of Biofilm Surface Roughness on Mass Transfer by Combining Optical Coherence Tomography and Two-Dimensional Modeling.Biotechnology and Bioengineering , 113 (5), 989-1000. https://doi.org/10.1002/bit.25868

Lin, M. H., Shu, J. C., Huang, H. Y., \& Cheng, Y. C. (2012). Involvement of iron in biofilm formation by staphylococcus aureus.PLoS ONE , 7 (3), 1-7. https://doi.org/10.1371/journal.pone.0034388

Manz, B., Volke, F., Goll, D., \& Horn, H. (2003). Measuring Local Flow Velocities and Biofilm Structure in Biofilm Systems With Magnetic Resonance Imaging (MRI). Biotechnology and Bioengineering ,84 (4), 424-432. https://doi.org/10.1002/10782

Martin, K., Bolster, D., Derlon, N., Morgenroth, E., \& Nerenberg, R. (2014). Effect of fouling layer spatial distribution on permeate flux: A theoretical and experimental study. Journal of Membrane Science , 471 , 130-137. https://doi.org/10.1016/j.memsci.2014.07.045

Mei, L., Liao, L., Wang, Z., \& Xu, C. (2015). Interactions between phosphoric/tannic acid and different forms of FeOOH. Advances in Materials Science and Engineering , 2015 , 1-10. https://doi.org/10.1155/2015/250836

Möhle, R. B., Langemann, T., Haesner, M., Augustin, W., Scholl, S., Neu, T. R., .. Horn, H. (2007). Structure and Shear Strength of Microbial Biofilms as Determined With Confocal Laser Scanning Microscopy and Fluid Dynamic Gauging Using a Novel Rotating Disc Biofilm Reactor.Biotechnology and Bioengineering , 98 (4), 747-755. https://doi.org/10.1002/bit

Möller, B., Glaß, M., Misiak, D., \& Posch, S. (2016). MiToBo - A Toolbox for Image Processing and Analysis. Journal of Open Research Software, 4 (1), 6-11. https://doi.org/10.5334/jors.103

Musk, D. J., Banko, D. A., \& Hergenrother, P. J. (2005). Iron Salts Perturb Biofilm Formation and Disrupt Existing Biofilms of Pseudomonas aeruginosa. Chemistry $\&$ Biology , 12 , 789-796. https://doi.org/10.1016/j.chembiol.2005.05.007

Neilands, J. (1974). MICORBIAL IRON METABOLISM (1st ed.). Elsevier.

Neu, T. R., Manz, B., Volke, F., Dynes, J. J., Hitchcock, A. P., \& Lawrence, J. R. (2010). Advanced imaging techniques for assessment of structure, composition and function in biofilm systems. FEMS Microbiology Ecology , 72 , 1-21. https://doi.org/10.1111/j.1574-6941.2010.00837.x

Oh, E., Andrews, K. J., \& Jeon, B. (2018). Enhanced biofilm formation by ferrous and ferric iron through oxidative stress in Campylobacter jejuni. Frontiers in Microbiology , 9 , 1-9. https://doi.org/10.3389/fmicb.2018.01204

Omoike, A., Chorover, J., Kwon, K. D., \& Kubicki, J. D. (2004). Adhesion of bacterial exopolymers to $\alpha$-FeOOH: Inner-sphere complexation of phosphodiester groups. Langmuir , 20 (25), 11108-11114. 
https://doi.org/10.1021/la048597

Park, A., Jeong, H.-H., Lee, J., Kim, K. P., \& Lee, C.-S. (2011). Effect of shear stress on the formation of bacterial biofilm in a microfluidic channel. BioChip Journal , 5 (3), 236-241. https://doi.org/10.1007/s13206011-5307-9

Paul, E., Ochoa, J. C., Pechaud, Y., Liu, Y., \& Liné, A. (2012). Effect of shear stress and growth conditions on detachment and physical properties of biofilms. Water Research , 46 (17), 5499-5508. https://doi.org/10.1016/j.watres.2012.07.029

Pelchovich, G., Omer-Bendori, S., \& Gophna, U. (2013). Menaquinone and iron are essential for complex colony development in Bacillus subtilis.PLoS ONE , 8 (11), 1-14. https://doi.org/10.1371/journal.pone.0079488

Peterson, B. W., He, Y., Ren, Y., Zerdoum, A., Libera, M. R., Sharma, P. K., .. Busscher, H. J. (2015). Viscoelasticity of biofilms and their recalcitrance to mechanical and chemical challenges. FEMS Microbiology Reviews , 39 (2), 234-245. https://doi.org/10.1093/femsre/fuu008

Purevdorj, B., Costerton, J. W., \& Stoodley, P. (2002). Influence of Hydrodynamics and Cell Signaling on the Structure and Behavior of Pseudomonas aeruginosa Biofilms Influence of Hydrodynamics and Cell Signaling on the Structure and Behavior of Pseudomonas aeruginosa Biofilms. Applied and Environmental Microbiology , 68 (9), 4457-4464. https://doi.org/10.1128/AEM.68.9.4457

Ranmadugala, D., Ebrahiminezhad, A., Manley-harris, M., \& Ghasemi, Y. (2017). The effect of iron oxide nanoparticles on Bacillus subtilis biofilm, growth and viability. Process Biochemistry , 62 , 231-240. https://doi.org/10.1016/j.procbio.2017.07.003

Renslow, R., Lewandowski, Z., \& Beyenal, H. (2011). Biofilm Image Reconstruction for Assessing Structural Parameters, 108 (6), 1383-1394. https://doi.org/10.1002/bit.23060.BIOFILM

Riemer, J., Hoepken, H., Czerwinska, H., Robinson, S. R., \& Dringen, R. (2004). Colorimetric ferrozinebased assay for the quantitation of iron in cultured cells. Analytical Biochemistry , 331 , 370-375. https://doi.org/10.1016/j.ab.2004.03.049

Rizzi, A., Roy, S., Bellenger, J. P., \& Beauregard, P. B. (2019). Iron homeostasis in Bacillus subtilis requires siderophore production and biofilm formation. Applied and Environmental Microbiology ,85 (3), 1-10. https://doi.org/10.1128/AEM.02439-18

Rosche, B., Li, X. Z., Hauer, B., Schmid, A., \& Buehler, K. (2009). Microbial biofilms: a concept for industrial catalysis? Trends in Biotechnology , 27 (11), 636-643. https://doi.org/10.1016/j.tibtech.2009.08.001

Rupp, C. J., Fux, C. A., \& Stoodley, P. (2005). Viscoelasticity of Staphylococcus aureus biofilms in response to fluid shear allows resistance to detachment and facilitates rolling migration. Applied and Environmental Microbiology , 71 (4), 2175-2178. https://doi.org/10.1128/AEM.71.4.2175-2178.2005

Safari, A., Tukovic, Z., Walter, M., Casey, E., \& Ivankovic, A. (2015). Mechanical properties of a mature biofilm from a wastewater system : from microscale to macroscale level. Biofouling , 31 (8), 651-664. https://doi.org/10.1080/08927014.2015.1075981

Schindelin, J., Arganda-Carreras, I., Frise, E., Kaynig, V., Longair, M., Pietzsch, T., ... Cardona, A. (2012). Fiji: An open-source platform for biological-image analysis. Nature Methods ,9 (7), 676-682. https://doi.org/10.1038/nmeth.2019

Sehar, S., Naz, I., Das, T., \& Ahmed, S. (2016). Evidence of microscopic correlation between biofilm kinetics and divalent cations for enhanced wastewater treatment efficiency. RSC Advances ,6 , 15112-15120. https://doi.org/10.1039/C5RA21076C

Singh, P. K. (2004). Iron sequestration by human lactoferrin stimulates P. aeruginosa surface motility and blocks biofilm formation. BioMetals , 17, 267-270. 
Singh, P. K., Parsek, M. R., Greenberg, E. P., \& Welsh, M. J. (2002). A component of innate immunity prevents bacterial biofilm development.Letters to Nature , 417, 552-555.

Song, B., \& Leff, L. G. (2006). Influence of magnesium ions on biofilm formation by Pseudomonas fluorescens. Microbiological Research ,161 (4), 355-361. https://doi.org/10.1016/J.MICRES.2006.01.004

Stoodley, P., Dodds, I., Boyle, J. D., \& Lappin-Scott, H. M. (1999). Influence of hydrodynamics and nutrients on biofilm structure. Journal of Applied Microbiology Symposium Supplement , 85 , 19-28.

Stoodley, P, Cargo, R., Rupp, C. J., Wilson, S., \& Klapper, I. (2002). Biofilm material properties as related to shear-induced deformation and detachment phenomena. Journal of Industrial Microbiology $\&$ Biotechnology , 361-367. https://doi.org/10.1038/sj.jim.7000282

Stoodley, Paul, Lewandowski, Z., Boyle, J. D., \& Lappin-scott, H. M. (1999). Structural Deformation of Bacterial Biofilms Caused by Short-Term Fluctuations in Fluid Shear : An In Situ Investigation of Biofilm Rheology.

Teodosio, J. S., Simoes, M., Melo, L. F., \& Mergulhao, F. J. (2011). Flow cell hydrodynamics and their effects on E. coli biofilm formation under different nutrient conditions and turbulent flow.Biofouling , 27 (1), 1-11. https://doi.org/10.1080/08927014.2010.535206

Towler, B. W., Rupp, C. J., Cunningham, A. L. B., \& Stoodley, P. (2003). Viscoelastic Properties of a Mixed Culture Biofilm from Rheometer Creep Analysis. Biofouling , 19 (5), 279-285. https://doi.org/10.1080/0892701031000152470

Van Loosdrecht, M. C. M., \& Heijnen, S. J. (1993). Biofilm bioreactors for waste-water treatment. Trends in Biotechnology , 11 (4), 117-121. https://doi.org/10.1016/0167-7799(93)90085-N

Wagner, M. (2011). Anwendung und Vergleich bildgebender Verfahren zur qualitativen und quantitativen Charakterisierung der Struktur von Biofilmen in der Mikro- und Mesoskala. Berichte aus der Siedlungswasserwirtschaft Technische Universitat Munchen 2011 . Technische Universitat Munchen. https://doi.org/ISSN 0942-914X

Wagner, M., \& Horn, H. (2017). Optical coherence tomography in biofilm research: A comprehensive review. Biotechnology and Bioengineering , 114 (7), 1386-1402. https://doi.org/10.1002/bit.26283

Wang, X., Wang, G., \& Hao, M. (2015). Modeling of the bacillus subtilis bacterial biofilm growing on an agar substrate. Computational and Mathematical Methods in Medicine , 2015 , 1-10. https://doi.org/10.1155/2015/581829

Weinberg, E. D. (2004). Suppression of bacterial biofilm formation by iron limitation. Medical Hypotheses , 63 , 863-865. https://doi.org/10.1016/j.mehy.2004.04.010

Weiss, N., Obied, K. E. T. El, Kalkman, J., Lammertink, R. G. H., \& van Leeuwen, T. G. (2016). Measurement of biofilm growth and local hydrodynamics using optical coherence tomography. Biomedical Optics Express , 7 (9), 3508-3518. https://doi.org/10.1364/boe.7.003508

Yang, L., Barken, K. B., Skindersoe, M. E., Christensen, A. B., Givskov, M., Tolker-nielsen, T., \& Tolkernielsen, T. (2007). Effects of iron on DNA release and biofilm development by Pseudomonas aeruginosa.Microbiology , 153 , 1318-1328. https://doi.org/10.1099/mic.0.2006/004911-0

Yang, X., Beyenal, H., Harkin, G., \& Lewandowski, Z. (2000). Quantifying biofilm structure using image analysis. Journal of Microbiological Methods , 39 (2), 109-119. https://doi.org/10.1016/S01677012(99)00097-4

Yeung, T., Kwan, M., Adler, L., Mills, T. J., Neilan, B. A., Conibeer, G., \& Patterson, R. (2017). Increased methane production in cyanobacteria and methanogenic microbe co-cultures. Bioresource Technology, 243 , 686-692. https://doi.org/10.1016/j.biortech.2017.06.126 
Tables

Table 1: Overview of conducted experiments.

\begin{tabular}{lllll}
\hline & \multicolumn{2}{c}{$\mathbf{c}_{\mathrm{Fe}^{2+}}$} & & $\mathbf{u}$ \\
Experiment & $(\mathrm{mg} / \mathrm{L})$ & $\mathbf{Q}(\mathrm{mL} / \mathrm{min})$ & $(\mathrm{cm} / \mathrm{s})$ & $(\mathrm{Pa})$ \\
\hline E1 & 2.5 & 1.0 & 0.75 & 0.05 \\
$\mathrm{E} 2$ & 0.25 & 1.0 & 0.75 & 0.05 \\
$\mathrm{E} 3$ & 2.5 & 5.0 & 3.75 & 0.27 \\
E4 & 0.25 & 5.0 & 3.75 & 0.27 \\
\hline
\end{tabular}

Table 2: Overview of all structural parameters used as well as their abbreviation, unit and interpretation.

\begin{tabular}{llll}
\hline Parameter & Abbr. & Unit & Interpretation \\
\hline Mean biofilm thickness & $L_{F}$ & $\mu \mathrm{m}$ & Biofilm height in z-direction; calculated from the bulk-biofilm interface to \\
Substratum coverage & $\mathrm{SC}$ & $\%$ & Coverage of the flow cell bottom with biofilm; $100 \%$ minus this paramete \\
Textural entropy & $\mathrm{TE}$ & - & Is a measure of the randomness of the pixel intensity distribution and thus \\
Fractal dimension & $\mathrm{FD}$ & - & Describes the irregularity of the aggregates surfaces; higher values equal h \\
Skewness & $R_{\mathrm{SK}}$ & - & Determines the occurrence of low (valleys; $\backslash n R_{\mathrm{SK}}<0$ ) and high biofilm col \\
Kurtosis & $R_{\mathrm{KU}}$ & - & Defines the distribution of these occurred valleys and hills on the biofilms \\
Average second moment & $\mathrm{ASM}$ & - & Direction orientated indicator of the cell clusters (higher values describe d \\
Inverse difference moment & $\mathrm{IDM}$ & - & Similar to ASM but distance orientated (lower values indicate that distanc \\
Average vertical run length & $\mathrm{AVRL}$ & $\mu \mathrm{m}$ & Mean colony width in y-direction; calculated from separated biofilm aggre \\
Average horizontal run length & AHRL & $\mu \mathrm{m}$ & Mean colony length in x-direction; calculated from separated biofilm aggre \\
\hline
\end{tabular}

Table 3: Two-factorial variance analysis of calculated structural biofilm parameters shown as $p$-values. $p<\alpha$ corresponds to a rejection of the hypothesis. $\mathrm{H}_{1}$ : no difference in structural biofilm parameters due to flow velocities. $\mathrm{H}_{2}$ : no differences caused by varied $\mathrm{Fe}^{2+}$ concentrations. $\mathrm{H}_{3}$ : no correlation between the two parameters $c$ and $u$.

Two-factorial variance analysis $(\alpha=0.01)$

\begin{tabular}{llll}
\hline & ANOVA & ANOVA & ANOVA \\
Structural parameter & $\mathbf{H}_{\mathbf{1}}$ & $\mathbf{H}_{\mathbf{2}}$ & $\mathbf{H}_{\mathbf{3}}$ \\
$L_{F}$ & 0.45 & $0.90 \cdot 10^{-4}$ & 0.24 \\
SC & 0.84 & $0.10 \cdot 10^{-4}$ & 0.57 \\
TE & 0.35 & $0.30 \cdot 10^{-5}$ & 0.24 \\
$R_{\mathrm{SK}}$ & 0.07 & $0.18 \cdot 10^{-2}$ & 0.61 \\
FD & 0.11 & $0.12 \cdot 10^{-4}$ & 0.43 \\
ASM & 0.63 & $0.27 \cdot 10^{-5}$ & 0.32 \\
IDM & 0.79 & $0.97 \cdot 10^{-5}$ & 0.55 \\
& Scheirer-Ray-Hare & Scheirer-Ray-Hare & Scheirer-Ray-Hare \\
Structural parameter & $\mathbf{H}_{\mathbf{1}}$ & $\mathbf{H}_{\mathbf{2}}$ & $\mathbf{H}_{\mathbf{3}}$ \\
$R_{\mathrm{KU}}$ & 0.16 & $0.56 \cdot 10^{-5}$ & 0.21 \\
AHRL & 0.17 & $0.12 \cdot 10^{-6}$ & 0.04 \\
AVRL & 0.78 & $0.17 \cdot 10^{-4}$ & 0.21 \\
\hline
\end{tabular}




\section{Figures}

Figure 1: Biofilm height maps (maximum intensity projections, MIPs) of day 10 comparing biofilms of each condition. The calibration bar resembles the biofilm height $\left(L_{F}\right)$ in $\mu \mathrm{m}$. The scale bar equals $1 \mathrm{~mm}$.

Figure 2: Comparison of the structural biofilm parameters mean biofilm thickness $L_{F}$, substratum coverage $\mathrm{SC}$, textural entropy TE, skewness $R_{\mathrm{SK}}$, kurtosis $R_{\mathrm{KU}}$, fractal dimensionFD, angular second moment ASM, inverse difference moment IDM, average horizontal AHRL and average vertical run length AVRL over the course of the experiments (10 days). Inoculation took place on day 0 . An overview and meaning of the parameters is provided in Table 2. $N=10$ replicates; E1/E3, [?] $c=2.5 \mathrm{mg} / \mathrm{L} \mathrm{Fe}^{2+} ; \mathrm{E} 2 / \mathrm{E} 4,[?] c=0.25$ $\mathrm{mg} / \mathrm{L} \mathrm{Fe}^{2+}$; opened data points [?] $u=0.75 \mathrm{~cm} / \mathrm{s}$; closed data points [?] $u=3.75 \mathrm{~cm} / \mathrm{s}$.

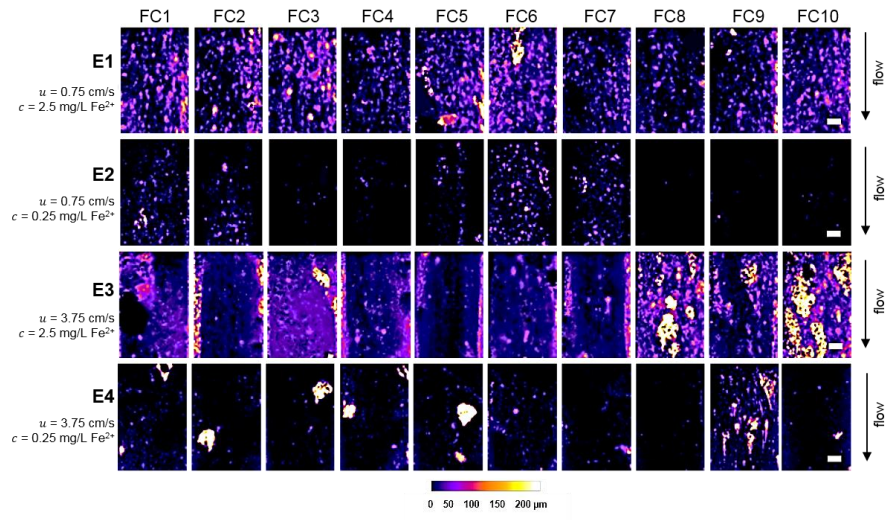




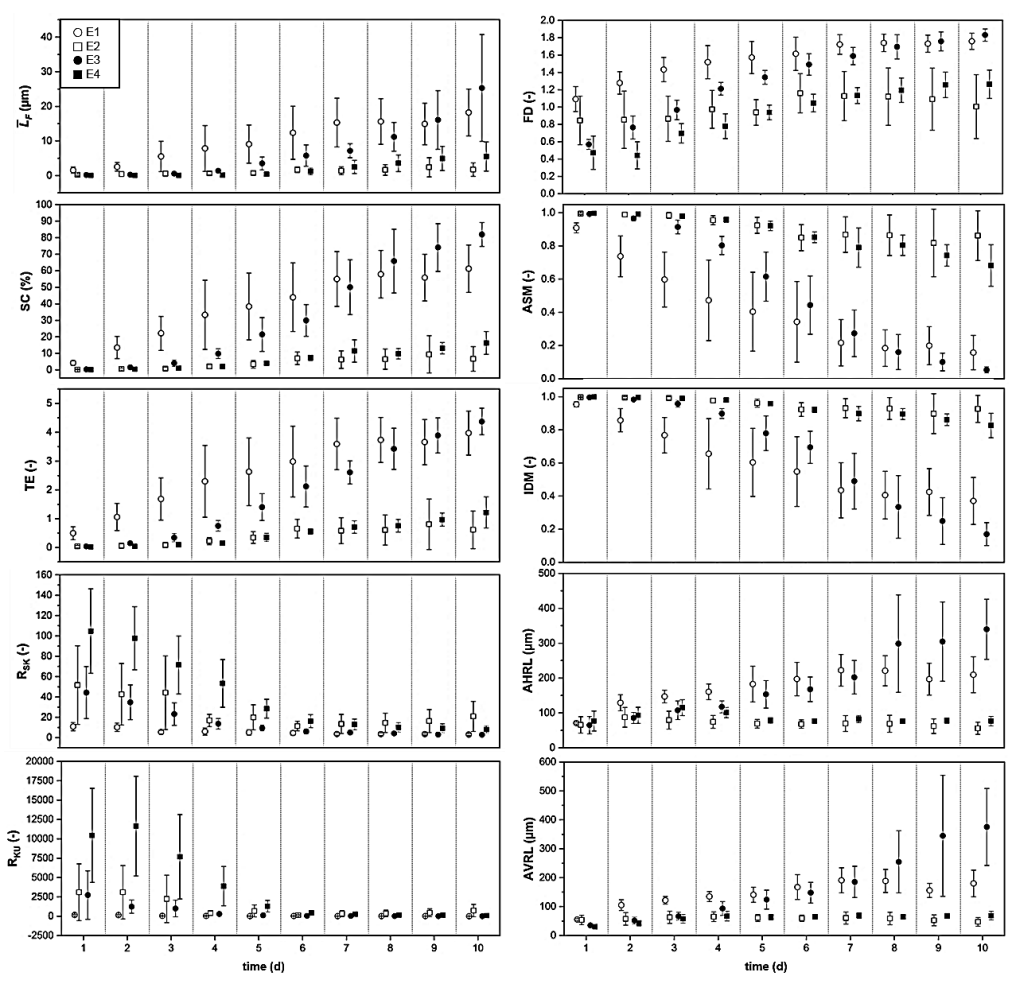

